\title{
Supply Chain Collaboration of High Pressure Pasteurization Processing Foods and Beverages
}

\author{
Jun Chen ${ }^{1, *}$, Dilin $\mathrm{Yao}^{2}$, Hui Chen ${ }^{3}$ \\ ${ }^{1}$ SHU-UTS SILC Business School, Shanghai University, Shanghai, China \\ ${ }^{2}$ School of Economics and Management, Shanghai Maritime University, Shanghai, China \\ ${ }^{3}$ Management School, Durham University, Durham, U.K
}

\section{Email address:}

robert_chenj@aliyun.com (Jun Chen), meiyiyao@hotmail.com (Dilin Yao), richardchh@hotmail.com (Hui Chen)

${ }^{*}$ Corresponding author

\section{To cite this article:}

Jun Chen, Dilin Yao, Hui Chen. Supply Chain Collaboration of High Pressure Pasteurization Processing Foods and Beverages. International Journal of Business and Economics Research. Vol. 6, No. 5, 2017, pp. 139-144. doi: 10.11648/j.ijber.20170605.18

Received: September 22, 2017; Accepted: October 28, 2017; Published: December 6, 2017

\begin{abstract}
This research chooses food that has shelf life as the object. The authors research on the best decision and coordination mechanism of members in supply chain from the customer choice behavior between food with different freshness and taste. Case studies are employed to construct the model of supply chain collaboration. This research not only has an important theoretical value on promoting the development of applying Chinese management science to the area of food industry and its internationalization, but also has great practical significance on strengthening the survival and development capacity and comprehensive international competitiveness of Chinese food industry and improving the social welfare.
\end{abstract}

Keywords: Supply Chain, Collaboration, High Pressure Pasteurization Processing

\section{Introduction}

The food industry is an important sector in the development of national economy. With the development of science and technology, various new methods of food processing and storage are researched and developed. Ultrahigh pressure food processing technology has just met people's demands for high-quality and high-nutritional food, and sparked a new revolution of food industry. What happens with it is that the domestication of equipment and design research of corresponding cold-chain logistics have become the bottleneck problems in the application of super-high pressure technique. This kind of bottlenecks will increase the access threshold for food enterprises to develop ultra-high pressure food. Meanwhile, solving the bottleneck problems can help food enterprises to enhance their core competitiveness. Ultra-high pressure food supply chain is the industrial chain research of various concerted supply chains, such as technology equipment, food and packing material. Food cold chain is a kind of special supply chain system, which covers the whole process from the perishable foods from origin acquisitions or fishing, in product processing, storage, transportation, distribution, retail, until transferred into consumers' hands. It is necessary to remain the products each link of the low temperature environment, to ensure the food quality and safety, reduce loss and prevent the contamination.

Color, taste and texture are not only the important quality characteristics of vegetables, fruit, seafood and meat, but also the main factors to affect the sensory quality as well as customer's acceptance of food. People apply various processing methods to increase the edibility and palatability of vegetable, fruit and meat besides extending their shelf life. Since the method of high pressure processing (HPP) exerts a very little influence on the covalent bond of food, its influence on the nutrition, taste, and texture of food is minimized. Therefore, HPP is an interesting choice for traditional food processing and fresh keeping. Specifically, HPP can promote the release of the protein in meat, eliminate part of the allergen and remove the pathogens [2]. In the ultra-high pressure processing, different pressures and temperatures can be used to gain the desired effect of food color, taste and texture. However, when the endogenous enzymes or microorganisms 
are not completely inactive, because of the coexistence of chemical reactions (such as oxidations and biochemical reactions), the quality of fruits and vegetables processed by high pressure will change in the stockpile period. Therefore, the cold chain should be designed based on how to prevent the above-mentioned chemical reactions. Meanwhile, food and juice treated by ultra-high pressure have higher requirements for the cold chain. Therefore, only through rational optimal design of cold-chain logistics can cost be reduced and shelf life and taste of products be increased, thus achieving the mass consumption of food processed by high pressure. Otherwise, food processed by ultra-high pressure can only be so-called high-grade food, and the cold chain innovation will only become a high-cost technology application.

The authors mainly research on how to ensure the improvement in color, taste and texture of foods like vegetables and fruit handled by HPP process through reasonable design and implementation, and to acquire the methods of improving the customer satisfaction and core competitiveness of enterprises by means of HPP process as well as cold chain production and transport for perishable food.

\section{Literature in HPP Food Supply Cold Chain Logistics}

The aim of cold chain logistics is to ensure the best quality of food to the utmost, not refrigeration [4]. The scope of fresh food cold-chain logistics includes not only primary agricultural products (vegetables, meat, poultry, eggs, aquatic products, horticultural products, etc.), but also processed food (frozen food, poultry, meat, aquatic products, packaging, deli, ice cream and dairy products, fast food and other raw materials), cold chain products can be divided into frozen, refrigerated and heated theses three stratospheres, according to different storage temperature requirements. The logistics of HPP processing foods and beverages belong to the fresh food cold-chain logistics which can improve the quality of food, taking the meat as an example (Table 1). At present, Chinese refrigeration capacity only account for $20 \%$ to $30 \%$ of the cargo demand, China's cold chain logistics industry has great business opportunities [12].

Table 1. Meat quality comparison chart.

\begin{tabular}{|c|c|c|c|}
\hline Item & $\begin{array}{l}\text { Chilled fresh meet } \\
(0 \sim 4 \text { degrees centigrade) }\end{array}$ & $\begin{array}{l}\text { Cold meat (18 degrees below } \\
\text { centigrade) }\end{array}$ & Hot meat (The meat at room temperature) \\
\hline Safety & $\begin{array}{l}\text { Full low temperature during production } \\
\text { and transportation, most safe to eat }\end{array}$ & $\begin{array}{l}\text { Harmful microorganisms are inhibited } \\
\text { and food is safer }\end{array}$ & $\begin{array}{l}\text { Harmful microorganisms are not inhibited } \\
\text { and extremely unsanitary }\end{array}$ \\
\hline Trophism & Nutrient absorption is most complete & $\begin{array}{l}\text { Ice crystals destroy meat tissue and } \\
\text { cause nutrient loss }\end{array}$ & $\begin{array}{l}\text { The meat is not mature, and nutrition does not } \\
\text { benefit for the body to absorb }\end{array}$ \\
\hline Flavor & Fresh and tender & Ordinary & Ordinary \\
\hline $\begin{array}{l}\text { Quality guarantee } \\
\text { period }\end{array}$ & Seven days & Twelve months & Half a day or even shorter \\
\hline
\end{tabular}

Source: www.shuanghui.com

Most literature reviews indicate that food cold chain logistics use the advanced technologies to carry out food production and distribution constructions, logistics process quality motion detection and tracking technologies, cold chain distribution and marketing of information technology. Furthermore, food cold chain also uses several of preservation techniques, such as mechanical refrigeration storage technology, gas storage and preservation withered technology, cellars preservation technology and preservative coating preservation techniques, etc. More advanced low humidity preservation, ozone atmosphere packaging, irradiation preservation, film preservation, preservation of high pressure, high temperature preservation, biological preservation, high-voltage electrostatic field preservation, pre-cooling technology and optical and classification techniques should be gradually adopted, to increase fresh food cold storage technology and reduce loss rate in transportation link. Therefore, the authors choose HPP processing as the research focus to find the link.

Since 1990 s, there have been several incidents related to food safety issues worldwide. From Sudan red, malachite green, formaldehyde to recycle milk, milk morning, to early 2008's Japanese poisoning dumpling, and then Sanlu milk powder incident, New Zealand Diary issues, these events about global food consumption are all in the field of food security and related to vulnerability on food safety, and these events also attract more and more attention from government and the consumers. As to the root causes of food safety issues, the food safety problems can be divided into two categories: one category is generated during the production of food safety issues, such as food-borne contamination or manufacturing process by the pollution; another is logistics process produces food safety issues, such as food safety problems caused by the food contaminated in the logistics process or food spoilage, rot which resulted from not being stored under refrigerated conditions, transportation, etc.. HPP technology can extend the shelf life, however during the manufacture process, HPP requires the proper pressure, temperature and humidity control; during the logistics process, HPP requires for cold-chain transportation, therefore, compared with the traditional food supply chain, you need supply chain collaboration among the various members.

Through cooperation and synergy, supply chain as an entirety gains a competitive advantage, provide high quality products and services to customers, and gain more profit distribution [10]. A new generation of supply chain strategy is 
collaborative supply chain [13]. Supply chain collaboration refers that member enterprises in the supply chain are coordinated synchronization to formulate planning and implementation strategy, sharing responsibility together [14]. The enterprise cooperation in Chinese cold chain logistics is rather loose, which leads to low efficiency and high cost [11]. Thus, the enterprise coordination is necessary in Chinese cold chain logistics [3], to pursue the common benefits and optimization of logistics performance [8]. Supply chain coordination level is divided into strategic layer coordination, tactical layer cooperation and operation layer cooperation [5, $6,7,9]$. HPP food cold chain system can be divided into the synergies of main supply chain members, facility collaboration and information collaboration comparing to traditional foods supply chain.

\section{Research Methodology}

The authors used semi-structured case study as the research methodology. They interviewed several key functional leaders at Xinjiang Kunlun Jade natural food engineering Company during the year from 2011 to 2017. Furthermore, they also interviewed and visited the distributors and $\mathrm{O} 2 \mathrm{O}$ retails as well as third party logistics service providers of Xinjiang Kunlun Jade Company to find the Supply chain collaboration relationship of HPP foods and beverages.

\section{Case Studies Findings}

In order to construct the cold chain collaboration model, the case study in Xinjiang Kunlun jade natural food engineering Co., Ltd. was conducted. This company was founded in June 2007, which is located in Xinjiang Kashgar Yue Pu Lake, covers an area of 139906.36 square meters. The total investment is RMB 135 million. The workshops are built in accordance with GMP with the annual output of 80 tons of freeze-dried donkey milk powder and annual output of 500 tons of HPP dairy products, annual output of 1000 tons of ultra-high pressure sterilization fresh pomegranate juice production line (at the same time for processing other fruit juice), annual output of 1000 tons of ultra-high pressure sterilization fresh dried fruit, annual output of 800 tons of health drink, annual output of 1000 tons of dried apricots. Jade Kunlun is focus on production technology management, quality management, research and development center, etc.

The Company has the overall rational layout, set up production area, living area, and logistics channels. The complete set of production equipment, testing equipment, perfect quality system, fire protection, environmental protection facilities are in strict alliance with the food safety requirements. Company has obtained six patents of invention, respectively is: 1) a donkey freeze-dried whole milk powder production method (certificate number: 1177809); 2) a drink and production methods of traditional Chinese medicines including donkey-hide gelatin (certificate number: 1177000); 3) The drink and production methods of traditional Chinese medicines containing donkey-hide gelatin (certificate number:
1190384); 4) The kind of drinks and production methods of traditional Chinese medicines containing donkey-hide gelatin (certificate number: 1190800); 5) The processing method of fresh jujube fruit the whole (patent number: 201010209681; 6) The pomegranate juice and its preparation method (certificate number: 1198881), another 5 patents of invention was declared in the public.

Adhere to the slogan of "science and technology as the source, innovation first, quality as priority", the Jade Kunlun strengthen cooperation with domestic scientific research institutions and universities, and get involved with China national 11th five-year plan "863 major projects". The company implemented non-thermal food super high-pressure technology into foods \& beverages research and development as well as production. Jade Kunlun has now formed a donkey dairy products series, fruit juice series, nuts series, series of health drinks with more than 30 varieties, such as dairy, fresh fruit juice, health drink, fresh fruit (dry), etc. These products are all HPP processed foods and beverages products, which do not contain additives. They are green, safe and rich nutrition with good taste.

The products do not contain any chemical additives without high temperature heat sterilization treatment, and can maximize keep food color, aroma, taste and nutrition of food with high quality as business duty. It has been proved to be the most difficult project to achieve the supply chain optimization and collaboration for the implementation of HPP production in foods and beverages. Through case studies, the findings would be interpreted as follows:

I. Cold chain logistics for the development of social economy resulted in a series of changes, affecting people's life in many ways. And as people attention to the problems of food quality and safety degree rise, more and more food production and marketing enterprises to realize the importance of cold-chain logistics, cold chain logistics has gradually become the effective way to improve enterprise competitiveness

II. Scientific food cold chain logistics management, can effectively maintain the freshness of goods, reduce product deterioration corruption problems brought about by the loss, reduce the waste of resources; At the same time improving the quality of the products but also to improve customer satisfaction, bring many benefits in various aspects.

III. Food cold chain logistics, inventory control and the traditional inventory control of the two main differences: one is the food cold chain inventory operation cost is higher; the other is to cold storage process can make the product rise, extend the shelf life of products.

IV. Food Safety issues. Comparing to HPP foods and beverages, there are no chemical additives add to the HPP foods and beverages. And through the HPP processing, the pathogenic bacteria and allergens have been killed, therefore the possibility of food safety occurrence become fewer and fewer. Thus, supply Chain cost loss can be controlled. The interesting thing is that half of the HPP foods and beverages supply chain members use RFID technology. The result of case study showed that: the convenience of RFID's reading and writing can help improve efficiency, reduce labor costs; 
using RFID cold-chain temperature management system to accomplish real-time monitoring and early warning mechanisms, can help reduce the deterioration loss during the flow and storage of goods, facilitate information tracing and contribute to the confirmation of responsibility in quality accidents; RFID cold-chain temperature management system can achieve end to end real-time temperature monitoring and recording, which can improve the safety of the food cold chain, and enhance consumer confidence, thus increasing the economic efficiency of enterprises. Comparing to the traditional HPP foods and beverages, HPP foods and beverages attach more importance to the execution of RFID technology.

V. Energy saving well to environment. Comparing to HPP, HPP foods and beverages will have less and less dependence on the external environment, such as the temperature and moisture. As a result, HPP process saves more energy and help to create the green environment. HPP process attaches more importance to cold chain logistics and led to the optimization of cold chain. According to the game theory, supply chain members achieve the new equilibrium during the HPP innovation.

VI. In recent years, the great increase in fresh food made the food distribution process more and more complex, and as people gradually increase the awareness of product quality, food cold-chain management has attracted more and more attention as a special and important part in logistics industry.

VII. Through the case study, the authors find that some of the enterprises use the ordinary vehicle to accomplish distribution of HPP products by putting the specific item inside into a system called incubator, and then adding the corresponding coolant to the incubator. In this case, they can reduce the large consumption and costs brought by using refrigerated trucks or frozen distribute simultaneously fresh, cooked fresh as well as other general merchandise which do not need specific temperature, and also ensure the quality and safety of goods. However, this method can only been used for the short distance delivery from distribution centers to bars and restaurants for the small quantity lot.

VIII. Furthermore, the authors find that the digital and intelligent controlling, environmentally friendly refrigerants and nitrogen making method, which use various forms of preservation technology support and development of new technologies such as temperature and atmosphere controls have become the effective ways to assure the supply chain implementation of HPP processing foods and beverages. The results showed that: the method provides a theoretical basis for the study of whole fresh fruits, vegetables, rice and meat logistics control system, improving the relative cold-chain circulation system and cold storage building.

IX. The KPIs of HPP foods and beverages logistics optimization include the following aspects: At first, minimizing total logistics costs; secondly, maximizing logistics speed; thirdly, optimizing the quality of customer service. The best practice of the case study companies indicates their successes lie in the balance of cost, speed and service. At present, China cold chain association is mainly responsible for the coordination and effective leverage of cold chain facility resource in China. According to the cold chain map, fresh food cold-chain logistics network has been divided into three modes: cold-chain logistics network of individual economies, regional and cross-regional network of cold-chain logistics network, each of these three cold chain logistics network has its own characteristics and scope. It is impossible for the HPP products manufacture and retailers to set up their own cold chain facilities due to the cost issue, therefore the supply chain implementation of HPP foods and beverages will accelerate the coordination of supply chain members horizontally and vertically. In view of the current weak and backward cold chain facility, in order to assure the smooth supply chain implementation of HPP foods and beverages, the implementation of joint distribution of cold chain logistics mode is an optimized selection.

Most of Foods and Beverage HPP processing manufactures in China are small and medium sized enterprises. They need to invest more to the business development with the limited capital funds. HPP production leads them to make changes to their supply chain management by forming the clusters to invest HPP machinery together and process together. In this case, they can share the HPP machinery cost and exchange the solution of the difficulties in the foods and beverages production. Before the implementation of HPP, most of the SME of foods and beverages in China tend to compete with cost leadership strategy. After using HPP for production, they formed the alliance by separating their products focus and achieve the mutual complimentary instead of competition. Therefore, more and more differentiation strategies are used in the enterprise; as a result, the new products are launched continuously to increase the entry level of HPP foods and beverages.

HPP foods cold chain logistics system is aimed at ensuring food quality, make maintenance of the low temperature environment as the core, and have higher requirements than the average room temperature logistics system, but also are more complicated. Firstly, compared with the normal logistics systems, HPP foods cold chain logistics system need larger construction investments. Secondly, the timeliness of the HPP foods requirements needs various aspects of the food cold chain logistics system has a higher organizational coordination, and higher operating efficiency. At present, China's food cold chain logistics system cooperation between all sectors of business is loose, without capability of collaboration, which lead to low efficiency, high cost, and can't effectively meet consumers' growing demands for food quality and safety. Therefore, from the enterprise level, to effectively solve issues existing in the process of food cold chain logistics system development, food cold chain logistics system synergy between various enterprises is required to achieve. This is because the food cold chain logistics system synergy means that the original fragmented enterprise integrates for the pursuit of common interests as a whole chain Through various enterprises working together to avoid and reduce the delays and waste in food cold chain logistics system, optimize performance, and achieves the overall goal. 
Here actually forms the HPP food supply chain members of ethnic groups as HPP cluster.

\section{The Cooperative Model of HPP Food Supply Chain}

The main purpose of cooperative research on supply chains is to design a reasonable coordination and interest allocation mechanism, which is in order to improve the performance of the whole supply chains and make the decentralized decision-making reach the effects same with centralized decision-making. At the same time, the "win-win" situation can be created. Then, toward the relatively special food supply chain, what is the strategy for pursuing the maximum performance of the whole supply chain? The case study shows that the traditional supply chain coordinating contracts (such as quantity discounts contract, buy-back contract, etc.) can also be applied to the field of ultrahigh pressure and traditional food supply chain, however, the differentiation also exists. Therefore, the research is designed according to variable situations to improve the coordinated safeguard mechanism

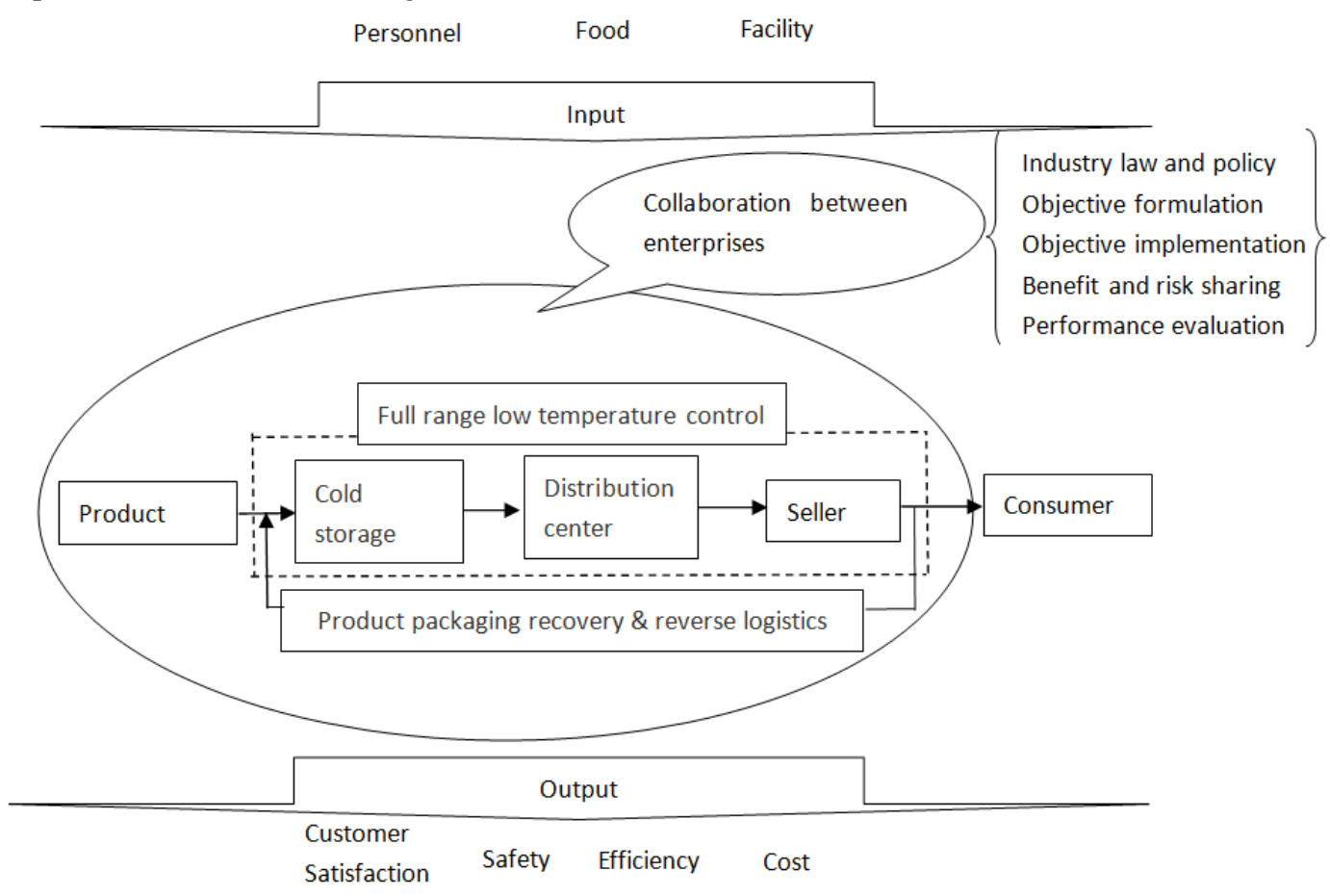

Figure 1. Model of Supply Chain Collaboration of High Pressure Processing Food.

\section{Conclusion and Future Research}

Hopefully, through this research, a series of theories and methods on the supply chain and cold chain management of high pressure pasteurization processed food can be established gradually, thus providing theoretical foundation and practical operation reference for supply chain management of related food production, distribution, wholesale and retail enterprises. The future study may aim to the synergies and collaborations of supply chain members of HPP foods and beverages, research in the optimization of supply chain members to and benefit distribution mechanism for raw material, packing material suppliers, food manufacturers, cold-chain logistics service providers and retailers so as to provide decision-making guidance for the operation of super high-pressure food supply chain. The model of supply chain collaboration of high pressure processing food is constructed (Figure 1). Products go through cold storage, distribution center and seller, finally achieving consumer with the reverse logistics and product packaging recovery after the point of seller returning back to the point of production recycling. The full range low temperature is controlled. Among the process from production to selling, enterprises would be collaborated, who follow the industry law and policy, formulate overall aims and implement them, share the benefits, profits and responsibilities, finally appraise the performance of supply chain coordination. With the supply chain synergy, personnel, foods and facilities are input. After the integration of supply chain cooperation of HPP foods, the customer satisfaction, food safety, management efficiency and profit would output. The optimization performance would be achieved with the coordinated supply chain.

Facility 
consumers' demand driven planning model of HPP foods and Beverages as the next step to solve the issue of inventory control of perishable HPP foods and beverages products.

\section{References}

[1] Chen, J. (2013), Supply Chain Core Competency of China Foods and Beverages Industry, Jilin People Publication Press, Changchun.

[2] Gong, X., Chang, J. and Li, D. T. (2014), "Development of ultra-high pressure fresh-keeping packaging technology", Packaging Engineering, Vol. 35 No. 3, pp. 97-101.

[3] Humphreys, P., Matthews, J. and Kumaraswamy, M. (2003), "Pre-construction project partnering: from adversarial to collaborative relationships", Supply Chain Management: An International Journal, Vol. 8 No. 2, pp. 166-178.

[4] James, S. J., James, C. and Evans, J. A. (2006), "Modeling of food transportation systems-a review", International Journal of Refrigeration, Vol. 29 No. 6, pp. 947-957.

[5] Liu, J. (2006), "Collaborative logistics research summary", Journal of Industrial Technological Economics, Vol. 25 No. 1, pp. 12-14.

[6] Liu, Y. and Nie, G. (2006), "A Logistics Knowledge Collaboration Model Based on Semantic Web", Journal of Wuhan University, Vol. 28 No. 9. pp. 11-14.

[7] Lu, Y., Z, Y. and Yang, L. (2006), "Research on Problems of Collaborative Decision in Supply Chain”, Logistics Sci-Tech, Vol. 29 No. 130, pp. 116-119.

[8] Robert, S. K. and David P. N. (2010), Alignment: using the balanced scorecard to create corporate synergies, The commercial press, Beijing.
[9] Wang, J. (2004), "Research on collaborative management of supply chain", Journal of Mechanical Transmission, Vol. 28 No. 4, pp. 67-69.

[10] Wang, Y. and Wang, Z. H. (2003), “Analysis of Complexity Lying in Modern Management System of Physical Distribution", Journal of Systemic Dialectics, Vol. 11 No. 4, pp. 88-91.

[11] Willimas, L. R., Esper, T. L. and Ozment, J. (2002), "The electronic supply chain: its impact on the current and future structure of strategic alliances, partnerships and logistics leadership", International Journal of Physical Distribution \& Logistics Management, Vol. 32 No. 8, pp. 703-719.

[12] Yuan, X., Zou, P., Zhu, J. and Wu, D. (2015), "Development Trend, Problems and Countermeasures for Cold Chain Logistics Industry in China”, Journal of Agricultural Science and Technology, Vol. 17 No. 1, pp. 7-14.

[13] Zhang, C. and Ren, J. (2005), "New-supply Chain Strategy: Collaborative Supply Chain", Journal of Northeastern University (social science), Vol. 7 No. 6, pp. 406-409.

[14] Zou, H. (2007), Supply chain collaborative management: theory and method, Peking University Press, Beijing.

[15] Sun, W, Li, J., Du, J., Zhu, S. and Yu, Y. (2016), “Adiabatic Compression Heating Characteristics of Selected Food Materials during High Pressure Processing”, Transactions of the Chinese Society for Agricultural Machinery, Vol. 47 No. 3, pp. 200-206.

[16] Yu, Y., Pan, F. and Su, G. (2015), “Application of ultra-high pressure on crop produces processing", Transactions of the Chinese Society for Agricultural Machinery, Vol. 46 No. 10, pp. 247-256. 